\title{
Preparation and Evaluation of Nutraceutical Product Mixture of Seeds of Cucumis melo, Punica granatum, Linum usitatissimum, for Antioxidant, Prebiotic and Nutraceutical Potential
}

\author{
Meera Chandradatt Singh ${ }^{1, *}$, Kishore N. Gujar ${ }^{2}$
}

Meera Chandradatt Singh ${ }^{1, *}$, Kishore N. Gujar ${ }^{2}$

'PhD Scholar(Pharmacy), PAHER's Pacific University, Udaipur Rajasthan Assistant Professor, S.T.E.S's S.K.N. College Pharmacy, Pune, Maharashtra, INDIA. ${ }^{2}$ Department of Pharmaceutics Principal and Professor, Sinhgad Technical Education Society's Sinhgad College of Pharmacy, Pune, Maharashtra, INDIA.

\section{Correspondence}

Mrs. Meera Chandradatt Singh

PhD Scholar, PAHER's Pacific University, Udaipur Rajasthan Assistant Professor,

S.T.E.S's S.K.N. College Pharmacy, Pune, Maharashtra, INDIA.

Phone no : +91 020- 24220059

E-mail: meerasingh2109@gmail.com

History

- Submission Date: 05-10-2018;

- Review completed: 18-12-2018;

- Accepted Date: 03-01-2019.

DOI : 10.5530/pj.2019.11.59

Article Available online

http://www.phcogj.com/v11/i2

\section{Copyright}

(C) 2019 Phcog.Net. This is an openaccess article distributed under the terms of the Creative Commons Attribution 4.0 International license.

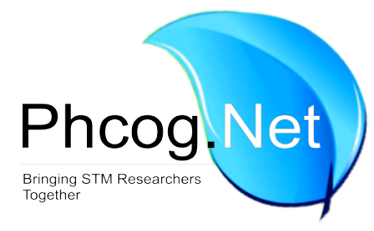

\begin{abstract}
Introduction: Pharmaceutical formulation scientists are currently developing new materials and formulations which vividly include Nutraceuticals. "Nutraceutical" is a substance that is considered a food or part of a food processed as pharmaceutical, which provides medical or health benefits, encompassing prevention and treatment of diseases. Materials and Methods: Under this research Nutraceutical Product Mixture was prepared using seeds of Cucumis melo, Punica granatum and Linum usitatissimum. Individually these three seeds are reported to contain rich nutrients along with antioxidants, probiotic soluble fibres and thus the mixture of three increased this potential. Individual seed and the mixture was evaluated by In-vitro and In-vivo methods for Nutraceutical Potential. Results: Proximate analysis of the mixture showed rich nutrient content and provided good combination of nutrients. Individual seed powder as well as mixture was tested for prebiotic potential using lactobacilli culture, which showed positive results. Each seed powder as well as mixture was tested for antioxidant potential using DPPH free radical scavenging assay, with promising results. It's in- vivo effect was studied using Wistar albino rat as animal model. This study involved haemogram and lipid profile determination which showed certain promising results. The powder mixture was developed into two products namely capsule and health drink powder formula. Conclusion: The nutraceutical powder mixture of seeds of Cucumis melo, Punica granatum and Linum usitatissimum could be a promising product with antioxidant, prebiotic and nutraceutical potential for diabetic and cardiac patients where oxidative stress is a major underlying cause. Key words: Nutraceuticals, Cucumis melo, Punica granatum, Linum usitatissimum, Antioxidant potential, Proximate analysis, Prebiotic potential, Nutraceutical potential.
\end{abstract}

\section{INTRODUCTION}

Pharmaceutical scientists are currently developing new materials and formulations in which nutraceuticals are a focus area. The term "Nutraceutical" was first defined by Dr. Stephen L. Defelice as "A product isolated or purified from foods and sold in medicinal forms" Nutraceutical is a combination of two words Nutrition and Pharmaceutical. ${ }^{1}$

According to AAFCO, 1996, 'Nutrient' means a food constituent in a form and a level that will help, support a life of human being or animal while 'Nutraceutical' means any non-toxic food component that has scientifically proven health benefits including prevention and treatment of disease. "Nutraceutical" is a substance that may be considered a food or part of a food which provides medical or health benefits, encompassing prevention and treatment of diseases. Products as diverse as isolated nutrients, dietary supplements, herbal products and processed foods (cereals, soups, beverages) may be included under the umbrella of nutraceuticals. In India, nutraceuticals have been defined under Clause 22 of the Food Safety and Standards Act (FSSA), 2006. ${ }^{3}$ Currently there is an increased global interest due to the recognition that "nutraceuticals" play a major role in health enhancement. ${ }^{4}$ Nutraceutical, functional food market in United States is 250 billion US\$ while drug market is 150 billion USD. Each year about 1000 new products come in US market. Global market for nutraceuticals is very huge and is growing further.

Under this research Nutraceutical Product Mixture was prepared using seeds of Cucumis melo, Punica granatum and Linum usitatissimu. Individually these three seeds are reported to contain rich nutrients and used in its raw form for nutraceutical and anti $\neg$ oxidant purpose. The dry seed powders and the mixture of the three were studied for nutrient content. This research combined these three seeds as they have varied nutrients and micronutrients and combination of these seeds powders in equal proportion gave better and comprehensive nutrient mixture. The seed powders were individually and as mixture were studied for proximate analysis, prebiotic

Cite this article: Singh MC, Gujar KN. Preparation and Evaluation of Nutraceutical Product Mixture of Seeds of Cucumis melo, Punica granatum, Linum usitatissimum, for Antioxidant, Prebiotic and Nutraceutical Potential. Pharmacog J. 2019;11(2):383-7. 
potential, DPPH assay for antioxidant potential and in vivo animal study. The promising results of these studies prompted this research to develop the powder mixture into two nutraceutical products namely capsule and health drink formula.

\section{MATERIALS AND METHODS}

\section{Preformulation Study}

\section{Procurement and Pre-treatment of Seeds}

Cucumis melo (Musk melon) and Punica granatum (Pomogranate) are common fruits abundantly available in India. Fresh fruits were purchased; seeds were separated from the pulp of the fruits, washed and dried to constant weight in shade. Linum usitatissimum, (Flax seeds) were ordered from a food supplier -Nutroactive. The seeds were authenticated from Botanical Survey of India (BIS/WRC/100-1/Tech./2018/111). The dried seeds were ground in a mixer grinder and passed through 85 number sieve.

\section{Bulk Powder Characteristics}

Following bulk powder characteristics were determined.

-Bulk density, Tapped density, \% compressibility, Hausner ratio and Flowability $^{5}$

A pre-weighed, presieved quantity of seed powder was poured into a graduated cylinder and the volume was recorded $\left(V_{0}\right)$. The cylinder was tapped for approximately till the final volume remained constant. The bulk and tapped densities were then calculated using the following equations.

Bulk Density (poured density): $m / V_{0}$, in g per $\mathrm{cm}^{3}$.

Tapped Density: $m / V \operatorname{tg}$ per $\mathrm{cm}^{3}$.

$$
\begin{aligned}
& \mathrm{m}=\text { weight of the powder } \\
& \mathrm{V}_{0}=\text { bulk volume }
\end{aligned}
$$

Carr's index $(\%)=($ Tapped density - Bulk density $) /$

Tapped density $\times 100$

The Carr's index is related to flow ability of the powder.

\section{Proximate Analysis of Nutraceutical Powder Mixture ${ }^{6-8}$}

Whole nutraceutical powder mixture was analyzed for moisture, crude protein, fats, crude fibers, ash, carbohydrates, calcium and iron. The recommended methods of the Association of Official Analytical chemists (AOAC, 1999) were used for the determination of crude proteins, carbohydrates, fats, fibres, calcium, iron, moisture. This study was conducted at National Agriculture and Food Analysis and Research Institute (NAFARI), Pune India, accredited Laboratory as per ISO/IEC 17025:2005 (Table 1).

\section{Determination of DPPH Radical Scavenging Properties $^{9-13}$}

All the Nutraceutical herbal powders were evaluated for antioxidant activity by DPPH assay. DPPH is 1,1-diphenyl-2-picryl hydrazyl, a stable free radical and contains a delocalized spare electron. The delocalisation also gives rise to the deep violet colour, characterised by an absorption band in methanol solution at about $520 \mathrm{~nm}$. When a solution of DPPH is mixed with a solution of substance that can donate a hydrogen atom, gives rise to the reduced form with the loss of violet colour.

Procedure: Jasco 630 UV-Spectrophotometer was used for the assay. Fresh DPPH stock solution $(0.004 \%)$ was prepared and stored in dark place until used. As a positive control, Quercetin $(50 \mathrm{mg} / 50 \mathrm{ml})$ was prepared in distilled water and serial dilutions $10,20,30,40,50 \mu \mathrm{g} / \mathrm{ml}$ were made. Test solutions of seeds were made in DMSO and allowed to react with DPPH solution at room temperature in dark place for $30 \mathrm{~min}$ then filtered and the absorbance values were measured at $517 \mathrm{~nm}$ against blank. The radical scavenging activity (\% inhibition) was expressed as \% of DPPH radical elimination, calculated according to the equation,

$\%$ Inhibition $=\frac{(\text { Absorbance of control }- \text { Absorbance of test })}{\text { Absorbance of control }} \times 100$

Concentrations were transformed to log concentrations and were plotted against $\%$ inhibition for five different concentrations. The equation was solved for $50 \%$ inhibition and by taking the antilog, the concentration required to cause $50 \%$ loss of DPPH activity $\left(\right.$ IC $_{50}$ in $\left.\mu \mathrm{g} / \mathrm{ml}\right)$ was calculated.

\section{Determination of Prebiotic Value of Nutraceutical Powders \\ Preparation of Nutrient Medium for Prebiotic Evaluation ${ }^{14,15}$}

Prebiotics are foods for probiotic bacteria which grow in intestine and improve gastrointestinal health along with many health benefits like decreased hypertension, cholesterol. Prebiotic potential of Cucumis melo L, Punica granatum, Linum usitatissimum and powder mixture was determined by Direct inoculation method. MRS nutrient media was positive control and plain agar medium was used as negative control. The following media were prepared for the prebiotic evaluation:

1. MRS nutrient media $25 \mathrm{ml}$

2. Plain agar medium $(25 \mathrm{ml})$

3. Plain agar $(25 \mathrm{ml})+$ Cucumis melo powder $(0.1 \mathrm{~g}$.)

4. Plain agar $(25 \mathrm{ml})+$ Punica granatum powder $(0.1 \mathrm{~g}$.)

5. Plain agar $(25 \mathrm{ml})+$ Linum usitatissimum powder $(0.1 \mathrm{~g}$.)

6. Plain agar $(25 \mathrm{ml})+1: 1: 1$ seed powder mixture $(0.1 \mathrm{~g})$

All nutrient media were sterilized in an autoclave for $15 \mathrm{~min}$ at $121^{\circ} \mathrm{C}$. The suspension of lactobacillus acidophilus was prepared. Aseptically, one $\mathrm{ml}$ of this suspension was added in all nutrient media in petriplates. All petriplates were transferred in the BOD incubator for 24 hand temperature of $37^{\circ} \mathrm{C}$ was maintained with anaerobic conditions. The growth of lactobacillus bacteria was observed after $48 \mathrm{~h}$. Refer Figure 2.

\section{Microbial Load Determination ${ }^{16}$}

$1 \mathrm{~g}$ nutraceutical powder mixture was mixed and stirred in $100 \mathrm{ml}$ sterile distilled water. One $\mathrm{ml}$ top clear liquid was pipetted out and diluted to $10 \mathrm{ml}$ with sterile distilled water. This procedure was repeated to get a dilution of $10^{-5}$. One $\mathrm{ml}$ of this final dilution was aseptically poured on to sterile petriplates containing Soybean casein agar medium. The plates were incubated at $37^{\circ} \mathrm{C}$ for $24 \mathrm{~h}$. The numbers of colony forming units were counted. The count was taken as the mean of duplicate determinations.

\section{Experimental Animals ${ }^{17,18}$}

Male albino Wistar rats, weighing 150-200 g were obtained from Smt. Kashibai Navale college of Pharmacy, Kondhwa, Pune. The animals were maintained under standard laboratory conditions at temperature $22 \pm 2{ }^{\circ} \mathrm{C}$, with relative humidity $55 \pm 10 \%$ and $12 \mathrm{~h}$ light, dark cycle throughout the experiment. Animals had free access to water and standard laboratory feed (Nutrivet life science, Pune) All the experimental procedures and protocols used in this study were received and approved (IAEC Protocol no: IAEC/2011) by the Institutional Animal Ethics Committee (IAEC) of S.K.N. college of pharmacy, Kondhwa, Pune 


\section{Experimental Design}

The study was carried out for 40 days. For experimentation; animals were randomly distributed into two groups. Group-I (NC): Normal control rats received normal feed diet.

Group-II: Experimental test group received nutraceutical powder mixture mixed with basic pallets.

The body weight of experimental animals was measured on $0,7^{\text {th }}, 14^{\text {th }}$, $21^{\text {st }} 28^{\text {th }} 35^{\text {th }} 40^{\text {th }}$ days and blood was tested at the end of 40 days.

\section{Formulation Development}

Formulations as health drink (for non-diabetic people) and capsule (for diabetic people) Nutraceutical powder mixture as a health drink was prepared by mixing seed powder mixture of Cucumis melo, Punica granatum and Linum usitatissimum 1:1:1 (50 g), Milk powder (30g), cocoa powder $(10 \mathrm{~g})$ and sucrose $(10 \mathrm{~g})$ - total $100 \mathrm{~g}$

\section{Manufacture of Capsules ${ }^{19}$}

1:1:1 seed powder mixture, the raw material for capsules was poorly flowing non-compressible powder and thus tablet dosage form was not possible. Therefore hard gelatine capsules that can accommodate $1 \mathrm{~g}$ were selected. Only 00 size capsules could accommodate $1 \mathrm{~g}$ of powder. On industrial scale a light compression will be needed to accommodate $1 \mathrm{~g}$ in 00 size capsules. 00 size capsules were manually filled and were evaluated for weight variation and disintegration test.

\section{RESULT AND DISCUSSION}

\section{Washing, Drying and Size Reduction}

The seeds of Cucumis melo, Punica granatum, Linum usitatissimum were washed and dried till the constant weight was obtained. Powder of Cucumis melo, Punica granatum, Linum were passed through 85\# sieve.

\section{Bulk Powder Characteristics}

All the three powders individually and as a mixture showed angle of repose more than $40^{\circ}$, Carr's index more than $25 \%$, Hausner ratio was more than 1.2, indicating poor flow and compressibility characteristics.

\section{RBC, Haemoglobin, Triglerides and VLDL Determination}

Table 1: Proximate analysis of the seed mixture sample.

\begin{tabular}{ccccc}
\hline $\begin{array}{c}\text { Sr } \\
\text { No }\end{array}$ & Parameter & Result & Units & Test method \\
\hline 1 & Proteins & 35.5 & $\mathrm{~g} / 100 \mathrm{~g}$ & AOAC 920.152 \\
2 & Carbohydrates & 33.42 & $\mathrm{~g} / 100 \mathrm{~g}$ & IS 1656.2012 \\
3 & Fat & 22.44 & $\mathrm{~g} / 100 \mathrm{~g}$ & IS 12711.2010 \\
4 & Crude fibre & 17.75 & $\mathrm{~g} / 100 \mathrm{~g}$ & IS 2234.2011 \\
5 & Soluble dietary fibre & 4.1 & $\mathrm{~g} / 100 \mathrm{~g}$ & IS 11062.2010 \\
6 & Iron & 22.67 & $\mathrm{mg} / 100 \mathrm{~g}$ & AOAC \\
7 & Calcium & 1620 & $\mathrm{mg} / 100 \mathrm{~g}$ & $944.02,320109$ \\
& & & & and 999.10 \\
8 & Fatty acid profile & & & \\
i & Saturated fat & 1.93 & $\mathrm{~g} / 100 \mathrm{~g}$ & AOAC 996.01 \\
ii & Monosaturated fat & 5.69 & $\mathrm{~g} / 100 \mathrm{~g}$ & \\
iii & Polysaturated fat & 14.82 & $\mathrm{~g} / 100 \mathrm{~g}$ & \\
iv & Trans fat & Not detected & $\mathrm{g} / 100 \mathrm{~g}$ & \\
$\mathrm{~V}$ & Omega 3 fatty acids & 34.13 & $\mathrm{~g} / 100 \mathrm{~g}$ & \\
\hline
\end{tabular}

\section{for 40 day Animal Study}

At the end of 40 days animal study, the Haemoglobin count of test group increased to $16.5 \mathrm{~g} \%$ from 12.1 whereas $\mathrm{Hb}$ in control group increased to $14.5 \mathrm{~g} \%$ from 11.5 . RBC count of test increased to $9.55 \mathrm{million} / \mathrm{mm}^{3}$ from 7.46 where as in control it decreased to 4.82 million $/ \mathrm{mm}^{3}$ from 6.38 , this attributes to the haemopoatic potential of this nutraceutical. It also showed relative icrease in level of plasma total protein concentration $(6.45 \mathrm{mg} / \mathrm{dl})$ which can be considered as health improvement parameter. The serum triglyceride level dropped to $77 \% \mathrm{mg}$ from 108 in test where as it increased to $115 \% \mathrm{mg}$ from 96 in control. The VLDL dropped to 15.4 \%mg from 21.6 in test where as it increased to $23 \% \mathrm{mg}$ from 19.2 in control. See Figure 1. This indicates that this nutraceutical can have potential in heart conditions and diabetes where high triglyceride and VLDL levels are seen in patients and where oxidative stress is the underlying reason.

\section{Determination of Antioxidant Activity}

The results are expressed as $\%$ inhibition, $\mathrm{IC}_{50}$ and quercetine equivalent. All the three active nutraceutical ingredients showed very high antioxidant potential and the prepared nutraceutical product shows excellent antioxidant potential. The results of the three seed powder mixture is shown in Table 2.

\section{Microbial Contamination Limit Test for Nutraceutical Powder Mixture}

Total Aerobic count $(\mathrm{TAC})=5 \times 10^{5} \mathrm{CFU}$ per gram

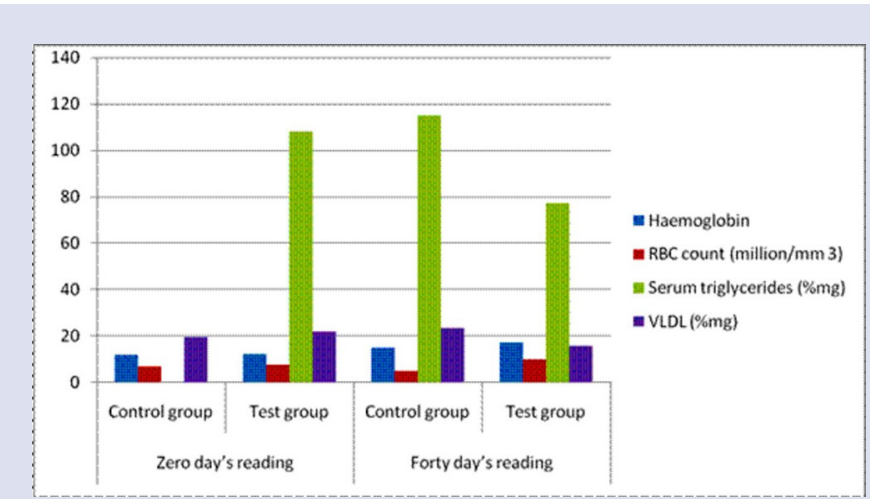

Figure 1: Impact on RBC, Haemoglobin, triglerides and VLDL determination for 40 day animal study.

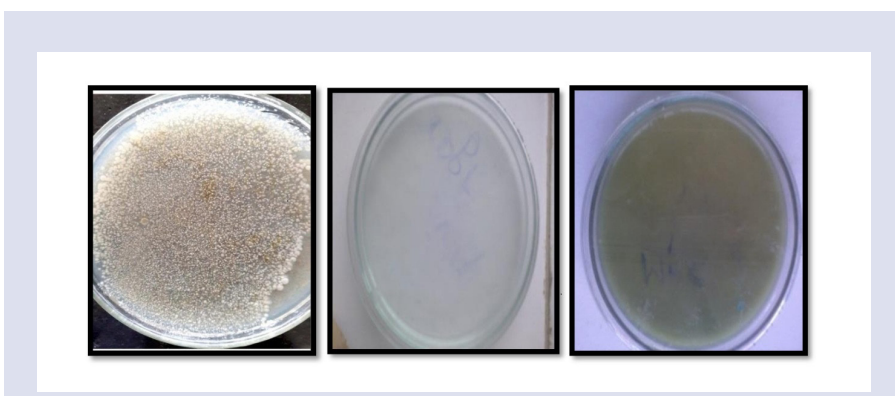

Sample- Growth B) Negative control - No growth C) Positive control- Growth

Figure 2: Prebiotic- potential determination. 
Table 2: \% inhibition( antioxidant potential) of nutraceutical powders.

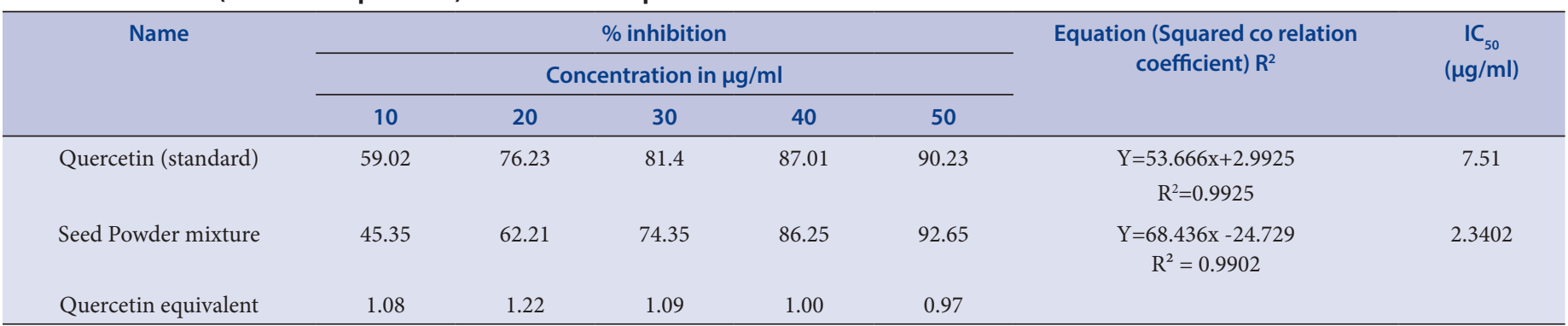

\section{Moisure Content}

Moisture content of seed mixture was found to be- $8.2 \%$.

\section{CONCLUSION}

The combination of seeds of Cucumis melo, Punica granatum and Linum usitatissimum as 1:1:1 mixture proved to be a potential nutraceutical mixture with rich macro and micro nutrients and antioxidants. The products mixture showed improved $\mathrm{RBC}, \mathrm{Hb}$ and lowering effect on triglyceride and VLDL levels in animal study. The DPPH assay shows remarkable antioxidant activity. In diabetes and cardiac diseases oxidative stress is the underlying reason which can be controlled with nutraceuticals like this. Thus this nutraceutical mixture can have applications in diabetes and heart disease management.

\section{ACKNOWLEDGEMENT}

I extend a deep gratitude towards Dr. S. D. Sawant, Principal, STES’s Smt. S K N college of Pharmacy, Pune for his constant encouragement and support.

\section{CONFLICT OF INTEREST}

The authors declare no conflict of interest.

\section{ABBREVIATIONS}

AOAC: Official Methods of Analysis of AOAC INTERNATIONAL; DPPH: 2,2-Diphenyl-1-picrylhydrazyl; CFU: Colony forming units; VLDL: Low density lipoproteins.

\section{REFERENCES}

1. Kalra EK. Nutraceutical - Definition and Introduction. The American Association of Pharmaceutical Scientists Pharm Sci. 2003;5(3):1-2

2. Dureja $H$, Kaushik D, Kumar V. Developments in Nutraceuticals. Indian Journal of Pharmacology. 2003;35(6):363-72.

3. Dudeja P, Gupta RK. Food Safety in the $21^{\text {st }}$ Century Public Health Perspective. First edition, Elsevier Inc. 2017;491-6.

4. Namdeo S, Bhaskar B, Sunil D, Pratik K. Nutraceuticals: A Review on current status. Research Journal of Pharmacy and Technology. 2014;7(1):110.

5. Michael E. Aulton and Kevin M.G. Taylor, Aulton's Pharmaceutics, The Design and Manufacture of Medicines. $3^{\text {rd }}$ edition, Churchill Livingstone. 2007;176-8.

6. The Official Methods of Analysis of AOAC INTERNATIONAL Gaithersbersburg, MD. [cited 2013 Feb19] Available from http://www.aoac.org/aoac_prod_imis/ AOAC/Publications/Official_Methods_of_Analysis/AOAC_Member/Pubs/OMA/
AOAC_Official_Methods_of_Analysis.aspx,2005.

7. Omar BH, Fouzia S, Naeema J. Studies on nutrition composition of coriander leaves by using sun and cabinet drying methods. International Journal of Chemical Studies. 2017;5(6):12-4

8. Hamdy AS, Shimaa A. Moawad Chemical composition, nutritional and functional properties of some herbs and spices. Current Science Perspectives. 2017;3(4):165-79.

9. Simran T, Amrita A, Sonali S, Jitender M, Shagun A. Antioxidant Profiling of Triticum aestivum (wheatgrass) and its Antiproliferative Activity in MCF-7 Breast Cancer Cell Line. Journal of Pharmacy Research. 2014;4(12). Available from: https://www.researchgate.net/.../261983482

10. Nur AM, Nusrat JB, Rafiquzzaman M. Review on in vivo and in vitro methods evaluation of antioxidant activity. Saudi Pharmaceutical Journal. 2013;21(2):143-52.

11. Moharram HA, Youssef MM. Methods for Determining the Antioxidant Activity: A Review. Alex Journal of Food Science and Technology. 2014;11(1):31-42.

12. Sunil DK, Jai CT, Acharya R, Nilima SR, DevasagayamTPA, Reddy AVR. Evaluation of the Antioxidant Activity of Wheatgrass (Triticum aestivum L.) as a Function of Growth under Different Conditions. Phytotherapy Research. 2006;20(3):218-27.

13. Neelofar K, Sharma GK. DPPH and ABTS Free Radical Scavenging Properties of whole leaf and inner gel extracts of Aloe vera. Indian Journal Life Science. 2015;5(1):97-106.

14. Sahar K, Mohammad R, Hosna H, Mahmoud B, Hassan H, Mahmoodnia L, et al. Isolation and identification of probiotic Lactobacillus from local dairy and evaluating their antagonistic effect on pathogens. International Journal of Pharm Investigation. 2017;7(3).

15. Lactobacillus MRS Agar Intended use -HiMedia Labs. [cited 2017, March]. Available from: http://himedialabs.com/TD/M641. \%2fTD\%2fM641.pdf\&oq.pdf

16. Indian Pharmacopoeia, Government of India ministry of health and family welfare Ghaziabad, Published by Indian Pharmacopoeia commission. 2010;(1):49,83,139,187, 1107-1108,1132.

17. Andre $H$, Michel $P$, Greet V. Food nutrition evaluation nutritional aspect of genetically modified foods. 2007;1-5. Available from: https://docplayer.net/20675293Food-nutrition-evaluation.htm

18. Edward KY, Eric CL, Royer A, Robert WL, Mark AM. Methods and systems for analysis of Nutraceutical associated components. US Patent No-7927787 B2 2011. Available from: https://app.dimensions.ai/details/patent/US-7927787-B2

19. Banerjee G, Mhaswade D. Prebiotic formulations and methods of use. US patent No- 2010/ 0297058. 2007. Available from: https://patents.google.com/ patent/US9579340

Cite this article: Singh MC, Gujar KN. Preparation and Evaluation of Nutraceutical Product Mixture of Seeds of Cucumis melo, Punica granatum, Linum usitatissimum, for Antioxidant, Prebiotic and Nutraceutical Potential. Pharmacog J. 2019;11(2):383-7. 
GRAPHICAL ABSTRACT

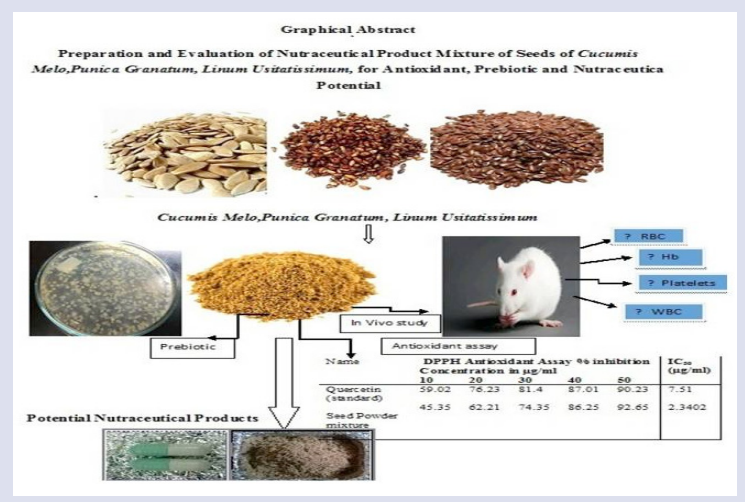

ABOUT AUTHORS

\section{SUMMARY}

- Nutraceutical research and formulation development is a promising new area in a pharmaceutical industry globally. This scope is under utilised in India till date. Good availability of variety of fruits and vegetables is under utilized for development of nutraceuticals in India. Under this research Nutraceutical Product Mixture was prepared using seeds of $o$, Cucumis melo, Punica granatum and Linum usitatissimum. Proximate analysis of the mixture showed good combination of nutrients. Individual seed powder as well as mixture was tested for prebiotic potential which showed positive results. Each seed powder as well as mixture was tested for antioxidant potential with promising results. It's in-vivo study involved haemogram and lipid profile determination which showed certain promising results. The powder mixture was developed into two products namely capsule and health drink powder formula. The nutraceutical powder mixture of seeds of Cucumis melo, Punica granatum and Linum usitatissimum could be a promising product with antioxidant, prebiotic and nutraceutical potential. Such nutraceuticals also can play good role in management of diabetes and cardiac diseases where oxidative stress is underlying reason.

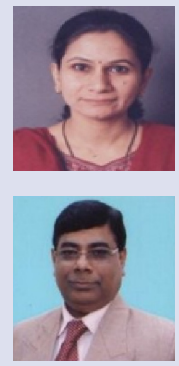

Mrs. Meera C. Singh, M. Pharm.( Q.A.) , Ph.D. scholar at PAHER's Pacific University, Udaipur. Currently working as an Associate Professor in Pharmaceutics,Department: Pharmaceutics,at S.T.E.S's Smt. Kashibai Navale College of Pharmacy, Kondhwa (Bk.), Pune, (Maharashtra) Areas of research interest are - Nutraceuticals, Prebiotics, Antioxidants, Nanoparticles, particulate DDS., Modified tablets, solubility enhancement of drugs.

Dr. K. N. Gujar, M.Pharm, Ph.D. (Pharmaceutics) Currently working as a Principal and Professor in Pharmaceutics, Department: Pharmaceutics, at S.T.E.S.'s Sinhgad college of Pharmacy, Vadgaon, Pune, (Maharashtra) Areas of research interest are - Nutraceuticals, Herbal formulations, Wound healing formulations, Phytochemicals and their dosage forms, particulate DDS, TDDS. 